\title{
Efeito da temperatura sobre o crescimento e esporulação in vitro de fungos hiperparasitas de Asperisporium caricae ${ }^{1}$
}

\author{
Janieli Maganha Silva Vivas², Marcelo Vivas², Silvaldo Felipe da Silveira ${ }^{2}$
}

\begin{abstract}
Effect of temperature on in vitro growth and sporulation of hyperparasites fungi of Asperisporium caricae

Black spot is the major papaya foliar fungal disease, being its chemical control necessary to achieve an economic commercial production. Alternative control methods, concerning fungicides, are necessary for the sustainable production of higher quality papaya fruits. Among them, biological control lacks basic studies. This study aimed to determine the proper temperature conditions for in vitro mycelial growth and sporulation of hyperparasites fungi isolated from Asperisporium caricae in papaya, which are potential biocontrol agents. A total of 18 fungal isolates (eight from Hansfordia pulvinata and ten from Acremonium spp.) were grown on PDA medium, at $15{ }^{\circ} \mathrm{C}, 20{ }^{\circ} \mathrm{C}, 23{ }^{\circ} \mathrm{C}, 25{ }^{\circ} \mathrm{C}$, $27^{\circ} \mathrm{C}$ and $30^{\circ} \mathrm{C}$, under a 12-hour photoperiod. For H. pulvinata isolates, mild temperatures around $21{ }^{\circ} \mathrm{C}$ result in maximum mycelial growth and sporulation. For Acremonium spp. isolates, the optimum temperature for mycelial growth and sporulation occurs at $20-25^{\circ} \mathrm{C}$.
\end{abstract}

KEY-WORDS: Carica papaya L.; Acremonium spp.; Hansfordia pulvinata.

\section{INTRODUÇÃO}

A pinta-preta do mamoeiro, causada por Asperisporium caricae (Speg.) Maubl., é uma das doenças fúngicas mais comuns e danosas, a qual apresenta expressiva importância econômica, pois provoca danos ao desenvolvimento da planta, afetando diretamente a superfície fotossintética das folhas, por meio de lesões arredondadas de coloração escura. Nos frutos, inicialmente, aparecem áreas circulares encharcadas, que evoluem para pústulas marrons e salientes, causando o endurecimento da casca, na parte afetada. Embora os sintomas sejam superficiais, as lesões os tornam inadequados à comercialização (Rezende \& Martins 2005).

\section{RESUMO}

A pinta-preta é a principal doença fúngica foliar do mamoeiro, sendo o controle químico necessário para se conseguir produção comercial econômica. Medidas de controle alternativas aos fungicidas são necessárias para a produção sustentável de frutos de mamão de melhor qualidade. Objetivou-se, neste trabalho, determinar as condições de temperatura adequadas ao crescimento micelial e à esporulação in vitro de fungos hiperparasitas do agente causal da pintapreta do mamoeiro, potenciais agentes de biocontrole. Foram avaliados 18 isolados fúngicos (oito de Hansfordia pulvinata e dez de Acremonium spp.), cultivados em meio BDA, às temperaturas de $15{ }^{\circ} \mathrm{C}, 20{ }^{\circ} \mathrm{C}, 23{ }^{\circ} \mathrm{C}, 25{ }^{\circ} \mathrm{C}, 27{ }^{\circ} \mathrm{C}$ e $30{ }^{\circ} \mathrm{C}$, sob fotoperíodo de 12 horas. Observou-se, para isolados de H. pulvinata, que temperaturas amenas (em torno de $21^{\circ} \mathrm{C}$ ) propiciam máximas de crescimento micelial e esporulação. Para os isolados de Acremonium spp., o ponto ótimo para crescimento micelial e esporulação ocorre no intervalo de 20-25 ${ }^{\circ} \mathrm{C}$.

PALAVRAS-CHAVE: Carica papaya L.; Acremonium spp.; Hansfordia pulvinata.

Dada a importância que a doença assume para a cultura, diferentes medidas de controle alternativas à pulverização de fungicidas são recomendadas. Essas medidas incluem a remoção de folhas senescentes (Suzuki et al. 2007), aplicação de fosfitos e indutores de resistência (Pratissoli et al. 2007, Dianese et al. 2008) e resistência genética (Dianese et al. 2007, Vivas et al. 2012, 2013a, 2013b). Apesar dos esforços empregados no desenvolvimento de métodos de controle da pinta-preta do mamoeiro, ainda não há uma medida alternativa que seja eficaz, sendo a pulverização com fungicidas uma prática constante, em campos de produção de mamão (Vawdrey et al. 2008, Barreto et al. 2011). 
Outra medida de controle que carece de estudos é o controle biológico. O biocontrole é considerado um método promissor para minimizar o uso de fungicidas e promover a proteção das culturas, pois se baseia em procedimentos ambientalmente corretos, que podem fazer parte de um sistema de controle integrado de doenças, e pode ser utilizado em sistemas de produção orgânica (Grigoletti Júnior et al. 2000, Slininger et al. 2003).

Em mamoeiro, essa possibilidade se consolida no fato de que há fungos hiperparasitas [gêneros Acremonium spp. Link e Hansfordia pulvinata (Berk. \& M.A. Curtis) S. Hughes] associados a lesões de pinta-preta do mamoeiro com potencial para o biocontrole de $A$. caricae.

No Brasil, a espécie $H$. pulvinata já foi estudada para o controle do mal-das-folhas da seringueira, causada por Microcyclus ulei (Hennings) Arx (Junqueira \& Gasparotto 1991), na lixa-grande e lixa-pequena do coqueiro (Warnick 2001, 2007), confirmando o potencial desse fungo para o controle das doenças citadas. Espécies de Acremonium já foram avaliadas como hiperparasitas dos agentes causais da lixa-pequena e lixa-grande do coqueiro (Sudo 1989, Warwick 2001) e apresentaram potencial de controle.

Para a cultura do mamoeiro, os estudos de biocontrole com hiperparasitas encontram-se em estágios iniciais, carecendo, pois, de estudos básicos, a fim de que se possa estabelecer condições ideais de cultivo, visando à produção massal de conídios, bem como condições climáticas e épocas do ano propícias à aplicação desses inimigos naturais.

Assim, objetivou-se, neste trabalho, avaliar o efeito da temperatura no crescimento micelial e esporulação de hiperparasitas do agente causal da pinta-preta do mamoeiro, sob cultivo axênico, em laboratório.

\section{MATERIAL E MÉTODOS}

O experimento foi conduzido no Laboratório de Entomologia e Fitopatologia da Universidade Estadual do Norte Fluminense Darcy Ribeiro, em Campos dos Goytacazes (RJ), de outubro a novembro de 2013.

Os fungos potenciais hiperparasitas foram obtidos por isolamento direto, em meio batata-dextrose-ágar(BDA), a partir de folhas de mamoeiro com lesões de pinta-preta e apresentando sinais do patógeno colonizado por hiperparasitas, coletadas em diferentes localidades dos Estados do Espírito Santo e Rio de Janeiro (Tabela 1).
Tabela 1. Relação dos isolados de fungos hiperparasitas de Asperisporium caricae observados em folhas de mamoeiro obtidas em diferentes locais e datas de coleta.

\begin{tabular}{|c|c|c|c|}
\hline Hiperparasita & Código & Local de coleta & $\begin{array}{c}\text { Data de } \\
\text { coleta }\end{array}$ \\
\hline \multirow{10}{*}{$\begin{array}{l}\text { Acremonium } \\
\text { sp. }\end{array}$} & A-598 & Alegre (ES) & $04 / 06 / 2012$ \\
\hline & A-601 & Alegre (ES) & $23 / 05 / 2012$ \\
\hline & A-602 & Mimoso do Sul (ES) & $02 / 07 / 2012$ \\
\hline & A-603 & Linhares (ES) & $29 / 12 / 2012$ \\
\hline & A-604 & Mimoso do Sul (ES) & $18 / 11 / 2012$ \\
\hline & A-609 & Campos dos Goytacazes (RJ) & $12 / 06 / 2012$ \\
\hline & A-616 & Alegre (ES) & $27 / 06 / 2012$ \\
\hline & A-617 & Cachoeiras de Macacu (RJ) & $21 / 11 / 2012$ \\
\hline & A-618 & Mimoso do Sul (ES) & $29 / 06 / 2012$ \\
\hline & A-619 & Mimoso do Sul (ES) & $26 / 09 / 2012$ \\
\hline \multirow{8}{*}{$\begin{array}{l}\text { Hansfordia } \\
\text { pulvinata }\end{array}$} & H-600 & Alegre (ES) & $27 / 06 / 2012$ \\
\hline & H-605 & Pesqueiro (SP) & $29 / 12 / 2012$ \\
\hline & H-608 & Mimoso do Sul (ES) & $04 / 06 / 2012$ \\
\hline & H-611 & Colatina (ES) & $26 / 09 / 2012$ \\
\hline & H-612 & Alegre (ES) & $29 / 06 / 2012$ \\
\hline & H-613 & Campos dos Goytacazes (RJ) & $23 / 05 / 2012$ \\
\hline & H-614 & Mimoso do Sul (ES) & $02 / 07 / 2012$ \\
\hline & H-615 & Cachoeiras de Macacu (RJ) & $18 / 11 / 2012$ \\
\hline
\end{tabular}

As culturas puras obtidas foram submetidas a isolamentos monospóricos, com o intuito de se garantir a pureza genética. Nesse procedimento, esporos diluídos em gota de água esterilizada foram espalhados em meio ágar $2 \%$, sob lâmina, com alça de Drigalsky, seguindo-se incubação em câmara úmida a $25^{\circ} \mathrm{C}$ e fotoperíodo de 12 horas. Sob microscópio óptico, esporos recém-germinados foram transferidos para meio BDA, em placas de Petri. As culturas foram mantidas em tubos com BDA a $10{ }^{\circ} \mathrm{C}$ (Dhingra \& Sinclair 1995), para utilização nos testes in vitro.

Com o auxílio de um furador de rolhas, foram retirados discos de $7 \mathrm{~mm}$ da porção mediana da colônia de culturas puras dos isolados em BDA, após 5 dias de incubação e fotoperíodo de 12 horas. Os discos da cultura dos 18 hiperparasitas (oito isolados de H. pulvinata e dez isolados de Acremonium spp.) cultivados em meio BDA foram transferidos para o centro de placas de Petri contendo $20 \mathrm{~mL}$ de BDA e incubados às temperaturas de $15^{\circ} \mathrm{C}, 20^{\circ} \mathrm{C}, 23^{\circ} \mathrm{C}$, $25{ }^{\circ} \mathrm{C}, 27{ }^{\circ} \mathrm{C}$ e $30^{\circ} \mathrm{C}$, sob fotoperíodo de 12 horas. $\mathrm{O}$ ensaio foi instalado em blocos casualizados, com arranjo em fatorial 18 (hiperparasitas) x 6 (temperaturas), com quatro repetições.

Avaliou-se, após 10 dias de incubação, o crescimento radial das colônias, medindo-se o diâmetro médio das colônias em dois sentidos ortogonais, sendo, posteriormente, obtida a média das 
duas medidas. Avaliou-se, também, a produção de conídios, em discos de $7 \mathrm{~mm}$ de diâmetro, retirados das culturas incubadas sob diferentes temperaturas. Para tal, com o auxílio de um furador de rolhas, discos de $7 \mathrm{~mm}$ de diâmetro foram retirados da região mediana das colônias e imersos em $1 \mathrm{~mL}$ de água com uma gota de solução Tween a $20 \%$, em tubos de vidro. Após agitação por 1 minuto, em agitador de tubos, retirou-se, com pipeta, a suspensão e procedeu-se à contagem em câmara de Neubauer (hemacitômetro).

Os dados de crescimento micelial e esporulação, nas diferentes temperaturas, foram submetidos à análise de variância. As variáveis significativas pelo teste $\mathrm{F}$ da análise de variância foram submetidas à análise de regressão linear. Para determinar a temperatura ótima ou o ponto de máximo crescimento micelial e esporulação, foi calculada a derivada de primeira ordem da equação de segundo grau ajustada por regressão (método dos quadrados mínimos).

\section{RESULTADOS E DISCUSSÃO}

Para os dois gêneros de fungos avaliados, houve interação significativa entre temperatura e isolados, tanto para o crescimento micelial quanto para a esporulação. Dessa forma, para as duas variáveis, foram conduzidas análises de regressão individual para cada isolado.

Todos os isolados de H. pulvinata apresentaram crescimento micelial na faixa de temperatura de 15-27 ${ }^{\circ} \mathrm{C}$. Porém, a $30^{\circ} \mathrm{C}$, somente os isolados H-613, H-608, H-611 e H-615 apresentaram crescimento, embora este não ultrapassasse $3,5 \mathrm{~mm}$ (Figura 1). A temperatura ótima para o maior crescimento micelial dos diferentes isolados variou entre $21{ }^{\circ} \mathrm{C}$ e $22{ }^{\circ} \mathrm{C}$. Essa diferença de $1{ }^{\circ} \mathrm{C}$ na resposta dos isolados sobre as diferentes temperaturas para crescimento micelial (Figura 1) aponta uma possível similaridade fisiológica dos diferentes isolados de $H$. pulvinata. Os resultados obtidos no presente estudo estão em consonância com os observados por Mello et al. (2005), os quais testaram a capacidade germinativa de $D$. pulvinata $(=H$. pulvinata), não constatando desenvolvimento de colônias à temperatura de $31^{\circ} \mathrm{C}$, após 17 dias de incubação.

Por outro lado, para os isolados de Acremonium spp., observou-se maior variação térmica $\left(20-25^{\circ} \mathrm{C}\right)$ de ótimo para crescimento micelial (Figura 2), sugerindo diferenças entre os isolados. Observou- -se, também, crescimento micelial de todos os isolados de Acremonium spp., às temperaturas de $15^{\circ} \mathrm{C}$ e $27^{\circ} \mathrm{C}$. Já à temperatura de $30^{\circ} \mathrm{C}$, a maioria dos isolados, mesmo que de forma reduzida, apresentou crescimento micelial, à exceção do isolado A-618 (Figura 2). Para a grande maioria dos isolados (A-618, A-602, A-598, A-604, A-601, A-619, A-616, A-603 e A-617), a temperatura ótima para crescimento micelial ficou entre $20^{\circ} \mathrm{C}$ e $22^{\circ} \mathrm{C}$ (Figura 2). Já para o isolado A-609, a temperatura ótima de crescimento micelial foi de $25{ }^{\circ} \mathrm{C}$, sendo que o crescimento máximo observado para esse isolado, nessa temperatura, foi de $29,5 \mathrm{~mm}$.

Acredita-se que temperaturas próximas à limítrofe para o crescimento dos isolados, como a de $30^{\circ} \mathrm{C}$, não foram responsáveis por matar o hiperparasita, uma vez que, em temperatura ambiente, os isolados presentes no interior das placas de Petri voltaram a apresentar crescimento micelial (dados não apresentados).

Os dados apresentados coincidem com as condições ambientais prevalescentes nas regiões e datas de coleta dos isolados. A maioria dos isolados foi obtida em épocas de temperaturas amenas. Segundo Rotem (1978), temperaturas extremas ou limítrofes são responsáveis por aumentar o tempo para iniciar uma epidemia. Aventa-se a possibilidade de o patógeno hiperparasitado $A$. caricae, nessas épocas, estar em franco desenvolvimento no campo.

Assim como observado para o crescimento micelial, quando se analisou a esporulação, constatou-se que os isolados de $H$. pulvinata apresentam preferência por temperaturas amenas, variando no intervalo de $19-22{ }^{\circ} \mathrm{C}$ (Figura 3). Assim, pode-se concluir que há uma pequena variação na temperatura ótima para esporulação entre eles. Os isolados H-608 e H-611 apresentaram ponto ótimo de esporulação à temperatura de $19^{\circ} \mathrm{C}$; H-600, H-605, H-612 e H-613 a $20{ }^{\circ} \mathrm{C}$; H-614 a $21{ }^{\circ} \mathrm{C}$; e H-615 a $22^{\circ} \mathrm{C}$.

A constatação de efeito significativo da interação entre os fatores isolados hiperparasitas e temperatura, tanto para crescimento micelial quanto para esporulação, é indicativo de que cada isolado responde de forma diferente às variações de temperatura.

Outros autores observaram diferenças no crescimento micelial e esporulação dos isolados, quando esses foram incubados a diferentes temperaturas, havendo maior crescimento e esporulação quando tais temperaturas eram amenas (Monteiro et al. 2004, Moreira \& Mayo 2007). Monteiro et al. 

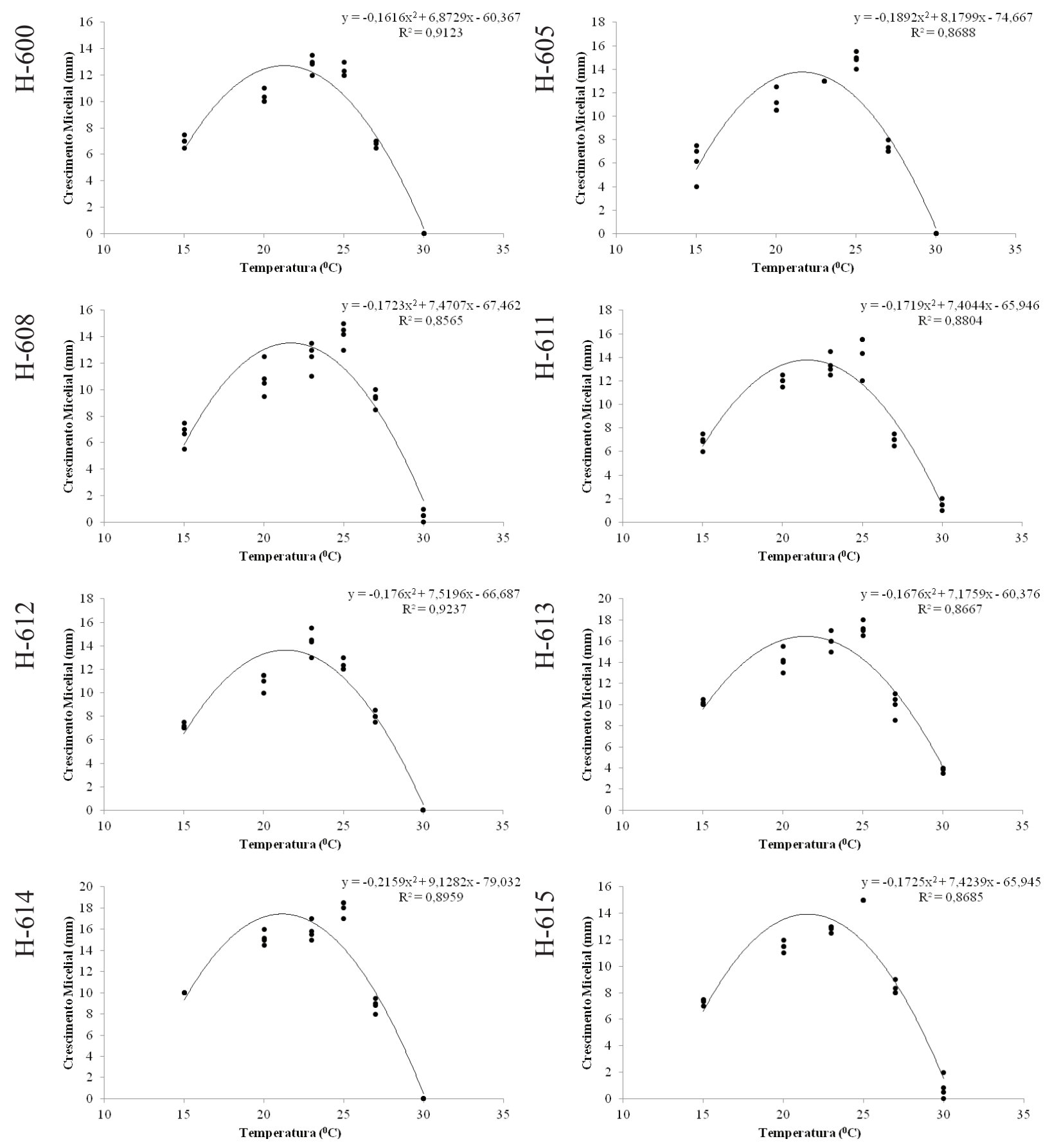

Figura 1. Crescimento micelial dos isolados de Hansfordia pulvinata, em função da temperatura, aos 10 dias de incubação em meio BDA (Campos dos Goytacazes, RJ, 2013).

(2004) constataram maior crescimento micelial e esporulação de Verticillium lecanii (Zimm.) Viégas às temperaturas de $19-25^{\circ} \mathrm{C}$. Moreira \& Mayo (2007) observaram que a faixa ótima de temperatura para o crescimento micelial de Monilinia fructicola (G. Winter) Honey e Trichothecium roseum (Pers.) Link foi de $20-25^{\circ} \mathrm{C}$.
Os resultados da esporulação para os isolados de Acremonium spp. indicaram que o isolado A-609 não teve sua produção de conídios reduzida, mesmo nas maiores temperaturas (Figura 4). Para esse isolado, não foi possível propor um modelo que descrevesse a relação entre temperatura e esporulação, entretanto, o modelo quadrático foi o que melhor se 

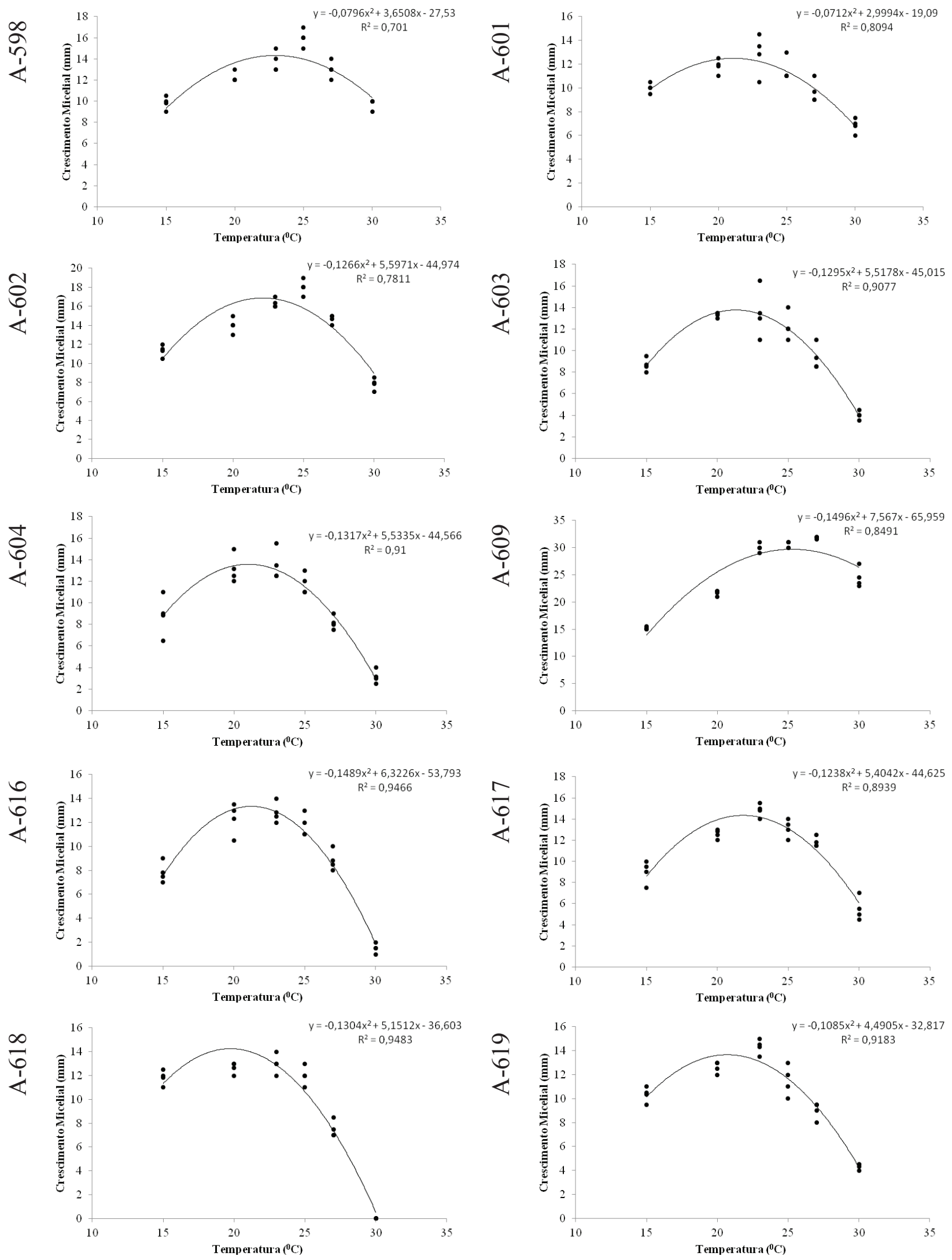

Figura 2. Crescimento micelial dos isolados de Acremonium spp., em função da temperatura, aos 10 dias de incubação em meio BDA (Campos dos Goytacazes, RJ, 2013). 

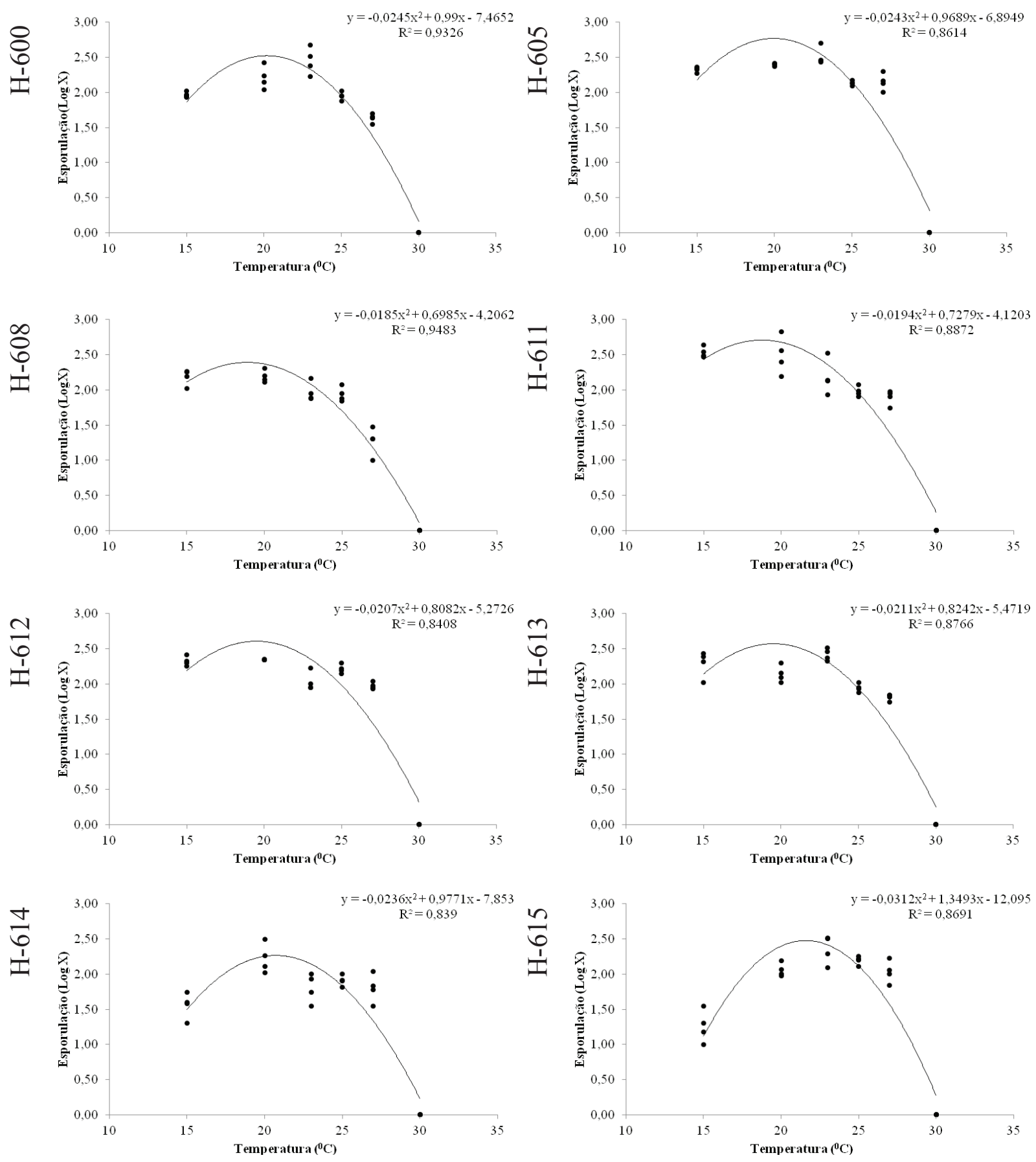

Figura 3. Produção de conídios dos isolados de Hansfordia pulvinata, em função da temperatura, aos 10 dias de incubação em meio BDA (Campos dos Goytacazes, RJ, 2013).

ajustou. Embora não tenha afetado a esporulação, ao se analisar o crescimento micelial desse isolado, observou-se que, na faixa de temperatura de $25-30^{\circ} \mathrm{C}$, o fungo apresentou menor crescimento micelial (Figura 2).

Pelos dados obtidos para o isolado A-609, aventa-se a possibilidade de a temperatura influenciar pouco a conidiogênese. Entretanto, essa hipótese deve ser observada com ressalvas, uma vez que a produção de conídios, para grande parte dos fungos, é dependente da massa micelial pré-existente (Sales-Campos \& Andrade 2010), considerando-se, ainda, que, no presente estudo, os conídios foram obtidos do centro de colônias com 10 dias, e que essas 

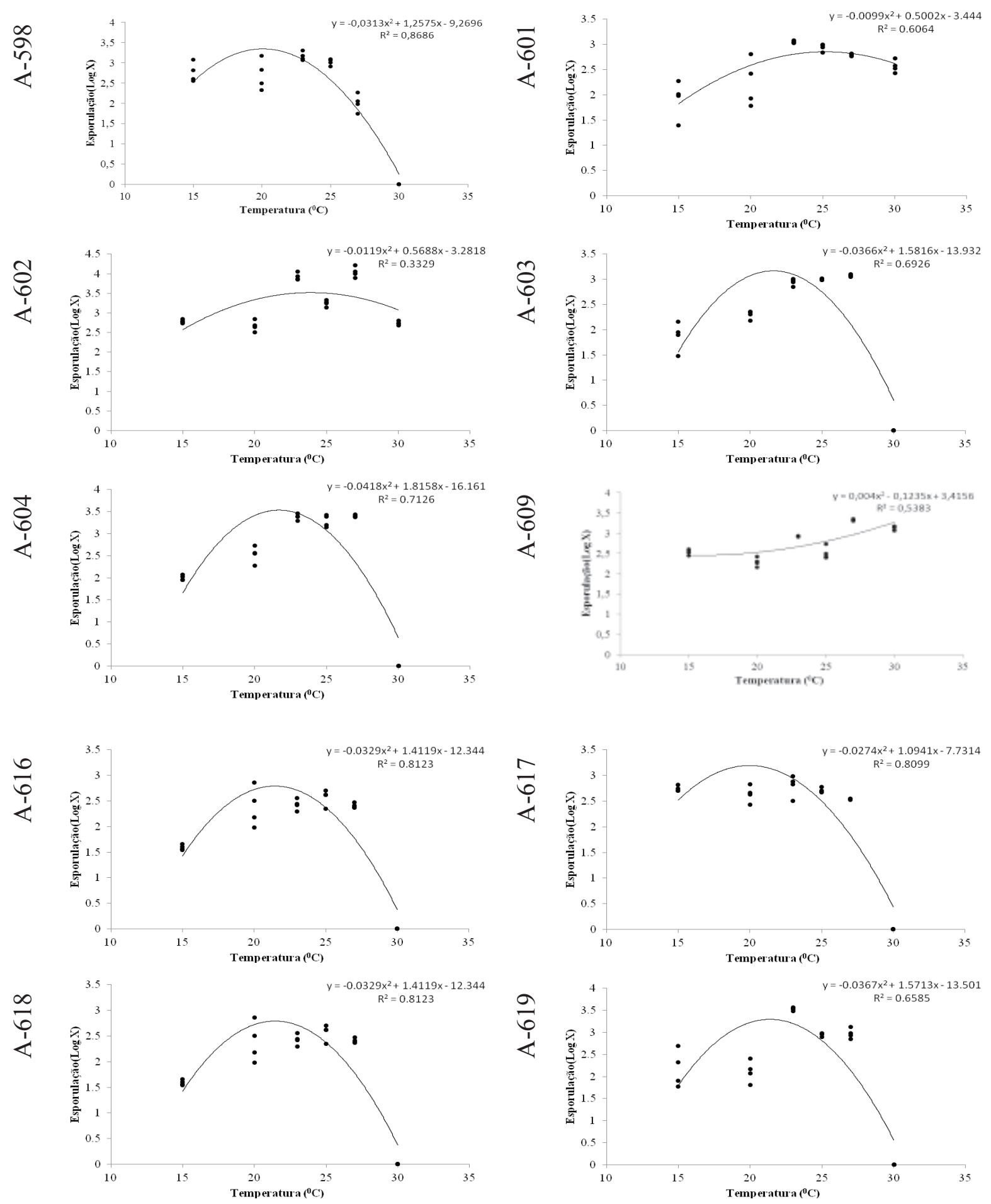

Figura 4. Produção de conídios dos isolados de Acremonium spp., em função da temperatura, aos 10 dias de incubação em meio BDA (Campos dos Goytacazes, RJ, 2013).

apresentaram maior ou menor crescimento micelial dependendo do isolado e das condições de cultivo (temperatura). Possivelmente, o resultado pudesse ser diferente, ao se avaliar a quantidade de conídios produzidos por placa. Por outro lado, não se pode deixar de informar que, para alguns fungos, o crescimento micelial abundante pode inibir, ou mesmo reduzir, a esporulação, sendo a avaliação do disco, 
ao invés da placa toda, uma forma de padronizar a mensuração da produção de conídios.

Para os demais isolados, observou-se que a temperatura ótima para esporulação variou entre $20^{\circ} \mathrm{C}$ e $22^{\circ} \mathrm{C}$. A temperatura de $20^{\circ} \mathrm{C}$ foi a que mais favoreceu a esporulação dos isolados A-598, A-618 e A-617, enquanto, para A-616, foi de $21{ }^{\circ} \mathrm{C}$ e, para A-604 e A-603, de $22{ }^{\circ} \mathrm{C}$ (Figura 4).

Os resultados evidenciam que, para a grande maioria dos isolados estudados de H. pulvinata e Acremonium spp., o crescimento micelial e a esporulação foram mais expressivos em temperaturas amenas $\left(20-22^{\circ} \mathrm{C}\right)$. A única exceção foi para os isolados A-609 de Acremonium spp., que apresentaram ótimo crescimento e esporulação a $25^{\circ} \mathrm{C}$. De todo modo, as temperaturas ótimas foram inferiores a $25^{\circ} \mathrm{C}$, tanto para crescimento micelial quanto para esporulação, sugerindo que as condições de verão, com temperaturas médias superiores a $25^{\circ} \mathrm{C}$, não seriam propícias à aplicação desses hiperparasitas. No entanto, testes adicionais em condições reais de cultivo fazem-se necessários para validar o que foi observado in vitro. Ademais, tem-se observado que, no verão, as epidemias de pinta-preta são menos severas.

\section{CONCLUSÕES}

1. A produção de inóculo, bem como o crescimento micelial e a esporulação de isolados de H. pulvinata, são maximizados sob temperaturas amenas em torno de $21^{\circ} \mathrm{C}$.

2. Para os isolados de Acremonium spp., o ponto ótimo para crescimento micelial e esporulação varia entre $20^{\circ} \mathrm{C}$ e $22{ }^{\circ} \mathrm{C}$, exceto para o isolado A-609, cuja temperatura ótima é de $25^{\circ} \mathrm{C}$.

\section{AGRADECIMENTOS}

À Fundação de Amparo à Pesquisa do Estado do Rio de Janeiro (FAPERJ), pelo suporte financeiro, e à Universidade Estadual do Norte Fluminense Darcy Ribeiro (UENF), pelo suporte financeiro e logístico.

\section{REFERÊNCIAS}

BARRETO, L. F. et al. Avaliação de fungicidas no controle de Asperisporium caricae na cultura do mamoeiro. Revista Brasileira de Fruticultura, Jaboticabal, v. 33, n. 1, p. 399403, 2011.
DHINGRA, O. D.; SINCLAIR, J. B. Basic plant pathology methods. 2. ed. Boca Raton: CRC Press, 1995.

DIANESE, A. C. et al. Avaliação do efeito de fosfitos na redução da varíola (Asperisporium caricae) do mamoeiro (Carica papaya). Revista Brasileira de Fruticultura, Jaboticabal, v. 30, n. 3, p. 834-837, 2008.

DIANESE, A. C. et al. Reação de genótipos de mamoeiro à varíola e à podridão-do-pé. Fitopatologia Brasileira, Lavras, v. 32, n. 5, p. 419-423, 2007.

GRIGOLETTI JÚNIOR, A.; SANTOS, A. F.; AUER, C. G. Perspectivas do uso do controle biológico contra doenças florestais. Revista Floresta, Curitiba, v. 30, n. 1, p. $155-165,2000$.

JUNQUEIRA, N. T. V.; GASPAROTTO, L. Controle biológico de fungos estromáticos causadores de doenças foliares em seringueira. In: BETTIOL, W. (Org.). Controle biológico de doenças de plantas. Jaguariúna: EmbrapaCNPDA, 1991. p. 307-331.

MELLO, S. C. M.; FRAZÃO, H. S.; SILVA, J. B. T. Capacidade germinativa e infectiva de isolados de Dicyma pulvinata antagônicos a Microcyclus ulei mantidos em coleção de cultura. Agrociência, Montevidéu, v. 9, n. 1-2, p. 421-426, 2005.

MONTEIRO, A. C. et al. Crescimento e esporulação de isolados de Verticillium lecanii sob diferentes fatores ambientais. Pesquisa Agropecuária Brasileira, Brasília, DF, v. 39, n. 6, p. 561-565, 2004.

MOREIRA, L. M.; MAYO, M. L. L. Crescimento micelial de Monilinia fructicola e Trichothecium roseum em diferentes temperaturas e sensibilidade do antagonista a fungicidas e fosfitos. Scientia Agraria, Curitiba, v. 8, n. 3, p. 337-341, 2007.

PRATISSOLI, D. et al. Fertilizante organomineral e argila silicatada como indutores de resistência à varíola do mamoeiro. Idesia, Arica, v. 25, n. 2, p. 63-67, 2007.

REZENDE, J. A. M.; MARTINS, M. C. Doenças do mamoeiro (Carica papaya L.). In: KIMATI, H. et al. (Eds.). Manual de fitopatologia: doenças das plantas cultivadas. São Paulo: Agronômica Ceres, 2005. p. 435443.

ROTEM, J. Climate and weather influence on epidemics. In: HORSFALL, J. G.; DIMOND, A. E. (Eds.). Plant disease: how disease develops in populations. New York: Academic Press, 1978. p. 317-436.

SALES-CAMPOS, C.; ANDRADE, M. C. N. Temperatura e meio de cultura mais favoráveis ao crescimento micelial de uma linhagem de Lentinus strigosus de ocorrência na Amazônia. Arquivos do Instituto Biológico, São Paulo, v. 77, n. 3, p. 539-543, 2010. 
SLININGER, P. J. et al. Discovery and development of biological agents to control crop pests. Neotropical Entomology, Londrina, v. 32, n. 2, p. 183-195, 2003.

SUDO, S. Biocontrole de Catacauma torrendiella e Coccostroma palmicola, agentes causadores da lixa preta do coqueiro. In: REUNIÃO BRASILEIRA SOBRE CONTROLE BIOLÓGICO DE DOENÇAS DE PLANTAS, 3., 1989, Piracicaba. Anais... Piracicaba: USP/ Embrapa, 1989. p. 57-59.

SUZUKI, M. S.; ZAMBOLIM, L.; LIBERATO, J. R. Progresso de doenças fúngicas e correlação com variáveis climáticas em mamoeiro. Summa Phytopathologica, Botucatu, v. 33, n. 2, p. 167-177, 2007.

VAWDREY, L. L.; GRICE, K. R. E.; WESTERHUIS, D. Field and laboratory evaluations of fungicides for the control of brown spot (Corynespora cassiicola) and black spot (Asperisporium caricae) of papaya in far north Queensland, Australia. Australasian Plant Pathology, Auckland, v. 37, n. 6, p. 552-558, 2008.
VIVAS, M. et al. Patometria, parâmetros genéticos e reação de progênies de mamoeiro à pinta-preta. Bragantia, Campinas, v. 71, n. 2, p. 235-238, 2012.

VIVAS, M. et al. Predição de ganhos genéticos e seleção de progênies de mamoeiro para resistência à pinta-preta. Tropical Plant Pathology, Brasília, DF, v. 38, n. 2, p. 142148, 2013a.

VIVAS, M. et al. Herança da resistência do mamoeiro a doenças fúngicas com base em análise dialélica de Hayman. Bragantia, Campinas, v. 72, n. 4, p. 332-337, 2013b.

WARWICK, D. R. N. Colonização de estromas de Sphaerodothis acrocomiae agente causal da lixa grande do coqueiro por Acremonium persicinum. Fitopatologia Brasileira, Brasília, DF, v. 26, n. 2, p. 220, 2001.

WARWICK, D. R. N. Índices de parasitismo de lixa-grande do coqueiro pelos fungos hiperparasitas Acremonium cavaraeanum e Dicyma pulvinata. Aracajú: Embrapa Tabuleiros Costeiros, 2007. 